\title{
The ground-based FTIR network's potential for investigating the atmospheric water cycle
}

\author{
M. Schneider ${ }^{1}$, K. Yoshimura ${ }^{2, *}$, F. Hase ${ }^{1}$, and T. Blumenstock ${ }^{1}$ \\ ${ }^{1}$ Karlsruhe Institute of Technology (KIT), IMK-ASF, Karlsruhe, Germany \\ ${ }^{2}$ Scripps Institution of Oceanography, University of California, San Diego, USA \\ *now at: Atmosphere and Ocean Research Institute, University of Tokyo, Kashiwa, Japan
}

Received: 26 November 2009 - Published in Atmos. Chem. Phys. Discuss.: 9 December 2009

Revised: 27 March 2010 - Accepted: 6 April 2010 - Published: 14 April 2010

\begin{abstract}
We present tropospheric $\mathrm{H}_{2}^{16} \mathrm{O}$ and $\mathrm{HD}^{16} \mathrm{O} / \mathrm{H}_{2}^{16} \mathrm{O}$ vapour profiles measured by ground-based FTIR (Fourier Transform Infrared) spectrometers between 1996 and 2008 at a northern hemispheric subarctic and subtropical site (Kiruna, Northern Sweden, $68^{\circ} \mathrm{N}$ and Izaña, Tenerife Island, $28^{\circ} \mathrm{N}$, respectively). We compare these measurements to an isotope incorporated atmospheric general circulation model (AGCM). If the model is nudged towards meteorological fields of reanalysis data the agreement is very satisfactory on time scales ranging from daily to inter-annual. Taking the Izaña and Kiruna measurements as an example we document the FTIR network's unique potential for investigating the atmospheric water cycle. At the subarctic site we find strong correlations between the FTIR data, on the one hand, and the Arctic Oscillation index and the northern Atlantic sea surface temperature, on the other hand. The Izaña FTIR measurements reveal the importance of the Hadley circulation and the Northern Atlantic Oscillation index for the subtropical middle/upper tropospheric water balance. We document where the AGCM is able to capture these complexities of the water cycle and where it fails.
\end{abstract}

\section{Introduction}

For understanding and predicting climate change it is necessary to understand the whole complexity of the Earth's climate system wherein the atmospheric water cycle plays a central role. Water participates in many processes that are crucial for the Earth's climate. By distribution of heat (vertically and horizontally), regulating surface temperature, formation of clouds, radiative forcing due to water vapour, etc., it widely determines the energy budget and thus the climate

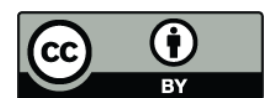

Correspondence to: M. Schneider (matthias.schneider@kit.edu) of our planet. Improving the climate models' treatment of the complex water cycle is one of the key goals set by the Intergovernmental Panel on Climate Change. In this context atmospheric water isotopologue ratios (e.g. $\mathrm{HD}^{16} \mathrm{O} / \mathrm{H}_{2}^{16} \mathrm{O}$ ) are of great interest. Various processes leave their imprint on the ratios: they are different, for instance, if evaporation happens from cold or warm ocean waters (and under dry or humid ambient conditions), from falling rain drops, from plants, or from the Earth's surface. Another example is recondensation while a humid air parcel moves to colder (higher) parts of the atmosphere. Then the vapour becomes gradually more depleted in heavy isotopologues (e.g. $\mathrm{HD}^{16} \mathrm{O}$ ), generally the more pronounced the colder the temperatures. The isotopologue ratios of water contain valuable information about the history of the water content and are thus a powerful tool for investigating the water cycle. In the following we express $\mathrm{H}_{2}^{16} \mathrm{O}$ and $\mathrm{HD}^{16} \mathrm{O}$ as $\mathrm{H}_{2} \mathrm{O}$ and $\mathrm{HDO}$, respectively, and $\mathrm{HD}^{16} \mathrm{O} / \mathrm{H}_{2}^{16} \mathrm{O}$ as $\delta \mathrm{D}=1000 \%$ $\times\left(\frac{\left[\mathrm{HD}^{16} \mathrm{O}\right] /\left[\mathrm{H}_{2}^{16} \mathrm{O}\right]}{\mathrm{SMOW}}-1\right)$, where SMOW $=3.1152 \times 10^{-4}$ (SMOW: Standard Mean Ocean Water, Craig, 1961).

Incorporating isotopologues in atmospheric general circulation models (AGCMs) provides unique opportunities to test and thereby improve the models' capability for reproducing the water cycle. Global long-term tropospheric isotopologue simulations are available for several different AGCMs (for an overview see Sturm et al., 2010), but so far this promising research field remains widely unexplored due to the lack of comprehensive long-term high quality observational data (the measurements have to be very precise due to the small natural variability of the ratios). Until very recently precise measurements of tropospheric upperair isotopologue ratios have been limited to sporadic campaigns (Ehhalt, 1974; Zahn, 2001; Webster and Heymsfield, 2003). Remote sensing techniques have the potential to provide quasi-continuous upper-air isotopologue ratio data. The sensors TES (Tropospheric Emission Spectrometer) and

Published by Copernicus Publications on behalf of the European Geosciences Union. 
SCIAMACHY (Scanning Imaging Absorption Spectrometer for Atmospheric Chartography) have provided the first quasicontinuous observation of tropospheric $\delta \mathrm{D}$, although for limited altitude ranges and time periods of a few years only (Worden et al., 2006; Frankenberg et al., 2009). In Schneider et al. (2006b) it is demonstrated that high quality groundbased FTIR (Fourier Transform Infrared) spectrometer measurements can be used to retrieve $\delta \mathrm{D}$ profiles between the surface and the middle/upper troposphere. These measurements have been performed for up to two decades at globally distributed sites within the NDACC (Network for Detection of Atmospheric Composition Change, Kurylo and Zander, 2000). The NDACC FTIR measurement records allow the generation of an unprecedented long-term dataset of tropospheric $\delta \mathrm{D}$ profiles.

In this paper we report tropospheric $\mathrm{H}_{2} \mathrm{O}$ and $\delta \mathrm{D}$ profiles measured by ground-based FTIR systems for up to 13 years at two very distinct sites: at the subarctic site of Kiruna and at the subtropical site of Izaña. We compare these measurements to the isotopologue incorporated AGCM, IsoGSM (Yoshimura et al., 2008). Section 2 briefly describes the measurement technique and the model. Section 3 presents the dataset, documents the difficulties faced when comparing observations and model, and the efforts taken to overcome these difficulties. The scientific outcome of our study is presented in Sect. 4. There we present measured and modelled annual cycles, anomalies on different time scales, and connections to large scale anomalies of sea surface temperature (SST) and atmospheric circulation. We reveal the unique potential of the FTIR technique for investigating the complexity of the atmospheric water cycle and document IsoGSM's capability of representing these complexities. Section 5 summarises the main results of our study.

\section{Measurement and model techniques}

\subsection{The ground-based FTIR measurement technique}

There are about 25 ground-based FTIR experiments performed within NDACC, including the Kiruna and Izaña experiments. These ground-based FTIR systems measure solar absorption spectra applying a high resolution Fourier Transform Spectrometer. The high resolution spectra allow an observation of the pressure broadening effect, and thus, the retrieval of trace gas profiles. The inversion problems faced in atmospheric remote sensing are in general ill-determined and the solution has to be properly constrained. An extensive treatment of this topic is given in the textbook of C. D. Rodgers (Rodgers, 2000).

The retrieval of tropospheric water vapour amounts from measured ground-based FTIR spectra is a particularly demanding atmospheric inversion problem and, due to its large vertical gradient and variability, standard retrieval setups are not suitable. The water vapour analysis applied for our study
Table 1. Estimated FTIR $\delta \mathrm{D}$ errors due to a $1 \%$ inconsistency between the $\mathrm{H}_{2} \mathrm{O}$ and $\mathrm{HDO}$ line parameters (random and systematic).

\begin{tabular}{lll}
\hline altitude domain & random & systematic \\
\hline column integrated & $5 \% 0$ & $<5 \% 0$ \\
lower troposphere & $15 \% 0$ & $10 \% 0$ \\
middle/upper troposphere & $30 \% 0$ & $40 \% 0$ \\
\hline
\end{tabular}

has been developed during recent years (for a review please refer to Schneider and Hase, 2009). It is based on the PROFFIT retrieval code (Hase et al., 2004), works with the water vapour mixing ratios on a logarithmic scale, and constrains the $\mathrm{HDO}$ and $\mathrm{H}_{2} \mathrm{O}$ ratios against each other, which is essential for an optimal estimation of tropospheric $\mathrm{H}_{2} \mathrm{O}$ and $\delta \mathrm{D}$ profiles (Schneider et al., 2006a,b). The $\mathrm{H}_{2} \mathrm{O}$ and $\delta \mathrm{D}$ profiles presented in the following are generated by analysing $\mathrm{H}_{2} \mathrm{O}$ and HDO signatures of the $1100-1330 \mathrm{~cm}^{-1}$ wavenumber range.

The errors of the FTIR $\mathrm{H}_{2} \mathrm{O}$ profiles have been theoretically and empirically assessed in great detail (Schneider et al., 2006a; Schneider and Hase, 2009; Schneider et al., 2010). They are smaller than $15 \%$ throughout the troposphere. The large amount of coincident radiosonde measurements applied in these inter-comparison studies assures the robustness of this error assessment.

A robust empirical validation of the FTIR $\delta \mathrm{D}$ profiles is not possible due to the lack of coincident reference measurements. Theoretically, most errors cancel out by taking the ratio between $\mathrm{HDO}$ and $\mathrm{H}_{2} \mathrm{O}$. As leading $\delta$ D error sources remain inconsistencies between the spectroscopic line parameters of $\mathrm{H}_{2} \mathrm{O}$ and $\mathrm{HDO}$ (Schneider et al., 2006b). An inconsistency between the line intensity parameters affects the $\delta \mathrm{D}$ profile rather uniformly, e.g., a $1 \%$ inconsistency causes an error of $10 \%$ o throughout the troposphere. On the other hand, an inconsistency between the pressure broadening parameters causes large errors in the $\delta \mathrm{D}$ profile shape. Table 1 lists the theoretical estimations for a $1 \%$ inconsistency. It predicts middle/upper tropospheric $\delta \mathrm{D}$ errors of about $40 \%$, whereby a positive error in the lower troposphere is correlated to a negative error in the middle/upper troposphere and vice versa. The inconsistency between the pressure broadening parameters - a systematic error source - is also responsible for most of the $\delta \mathrm{D}$ random error. This at a first glance surprising result can be explained by the large nonlinearities involved in ground-based water vapour retrievals. For more details please refer to the extensive discussion in Schneider et al. (2006b). 


\subsection{The isotope-incorporated atmospheric general cir- culation model IsoGSM}

IsoGSM is an isotope incorporated AGCM based on an up-to-date version of the Scripps Experimental Climate Prediction Centre's Global Spectral Model (ECPC's GSM; Kanamitsu et al., 2002). IsoGSM offers two options for performing the simulations. First, a free run in which the model is only driven by the SST. This is how common AMIP-type (Atmospheric Model Intercomparison Project; Gates, 1992) AGCMs operate. And second, a nudged run in which the model is nudged towards NCEP (National Centers for Environmental Prediction) reanalysis large scale horizontal wind and temperature fields (Yoshimura and Kanamitsu, 2008). Please note that water vapour is not nudged. i.e. the model remains its own hydrological cycle. Nudging is important when comparing the model to measurements, since tropospheric water vapour and its isotopic composition strongly vary with the actual synoptic situation. The nudging technique adjusts the model dynamics to the actual short term synoptic scale situation and allows an adequate simulation of day-to-day as well as inter-annual variability.

The horizontal resolution of the model is T62 (about $200 \mathrm{~km}$ ) and the vertical resolution is 28 sigma-level layers. The output is in 17 pressure-level grid points, i.e. 1000, 925, $850,700,600,500,400,300,250,200,150,100,70,50,30$, 20 , and $10 \mathrm{hPa}$. For more details please refer to Yoshimura et al. (2008). IsoGSM data from a nudged run as well as from a free run (nudging turned off) are available on a global scale since 1979 with a temporal resolution of $6 \mathrm{~h}$. Time series for 1996 to 2008 of nudged run data are shown in Figs. 1 and 2 as red crosses.

\section{Presentation of the dataset}

\subsection{Subarctic site of Kiruna}

Figure 1 shows the time series of measured and simulated $\mathrm{H}_{2} \mathrm{O}$ and $\delta \mathrm{D}$ data for the subarctic NDACC site of Kiruna (Northern Sweden, $67^{\circ} 50^{\prime} \mathrm{N}, 20^{\circ} 25^{\prime} \mathrm{E}$ at $420 \mathrm{~m}$ a.s.l.; e.g. Blumenstock et al., 2006). The ground-based FTIR measurements have been performed since March 1996 on a regular basis applying a Bruker IFS 120HR spectrometer. Typically there are about 80 measurement days per year. The gaps in the years 1999, 2000, 2004, and 2008 are due to the extremely stringent measurement quality that has to be required for isotopologue analysis. In the corresponding spectra we detect a small baseline offset (of about $1 \%$, derived by analysing saturated water vapour signatures). It will be corrected in a future reevaluation and the data gaps for the corresponding years will be minimised.

We present the total precipitable water vapour (PWV) amounts and the column integrated $\delta \mathrm{D}$ values, as well as the $\mathrm{H}_{2} \mathrm{O}$ volume mixing ratios (VMRs) and $\delta \mathrm{D}$ values for the lower free troposphere, and the middle troposphere, represented by the altitudes of 1 and $4 \mathrm{~km}$, respectively. Concerning $\mathrm{H}_{2} \mathrm{O}$ we observe a very prominent annual cycle in both measurements and simulations. There are some small systematic differences: close to the surface the modelled water vapour amounts are slightly lower than the measured amounts and in the middle troposphere the modelled amounts are slightly larger than the measured amounts. Concerning $\delta \mathrm{D}$ we observe more variability in the measurement as compared to the model. In the middle troposphere $(4 \mathrm{~km})$ there is a large systematic difference. Whereas the $\delta \mathrm{D}$ values simulated for $4 \mathrm{~km}$ are confined between -200 and $-500 \%$, the measured values are situated between $\pm 0 \%$ in summer and $-400 \%$ in winter.

\subsection{Subtropical site of Izaña}

The time series of simulation and measurements for the NDACC site of Izaña (Tenerife Island, Spain, $28^{\circ} 18^{\prime} \mathrm{N}$, $16^{\circ} 29^{\prime} \mathrm{W}$ at $2370 \mathrm{~m}$ a.s.l.; e.g. Schneider et al., 2008) are depicted in Fig. 2. We show $\mathrm{H}_{2} \mathrm{O}$ and $\delta \mathrm{D}$ data for altitudes of 3 and $7 \mathrm{~km}$, which are representative for the lower free and the middle subtropical troposphere and for the column integrated atmosphere. The FTIR measurements started in March 1999 using a Bruker IFS $120 \mathrm{M}$ spectrometer. In January 2005 the IFS $120 \mathrm{M}$ was replaced by a Bruker IFS $120 / 5 \mathrm{HR}$ spectrometer. As for Kiruna we apply a very stringent measurement quality criterion. The FTIR $\delta \mathrm{D}$ profile data are limited to 4 years, since the IFS $120 \mathrm{M}$ measurements, performed in the $1000-1330 \mathrm{~cm}^{-1}$ range do generally not reach the high signal to noise ratio that is required for measuring $\delta \mathrm{D}$ profiles. In the near future we hope to close these gaps by an additional analysis of $\mathrm{H}_{2} \mathrm{O}$ and HDO signatures in the 2600 $3100 \mathrm{~cm}^{-1}$ wavenumber range, where the signal to noise ratio is significantly higher.

The annual $\mathrm{H}_{2} \mathrm{O}$ cycles are less pronounced than in Kiruna. The PWV measurements and simulations agree very well. Similar to Kiruna we observe a slight dry bias of the model with respect to the measurement in the lower troposphere and a wet bias in the middle troposphere. Both measurement and simulation observe a maximum in $\delta \mathrm{D}$ in summer and a minimum in winter. However, similar to Kiruna, the amplitude of the cycle is larger for the measurements if compared to the simulations. Furthermore there is a systematic difference between the middle tropospheric $\delta \mathrm{D}$ values: whereas the mean measured $\delta \mathrm{D}$ value is $-210 \%$, the mean simulated value is $-260 \%$.

\subsection{Disparity between FTIR and IsoGSM data}

When comparing model and remote sensing data it is important to think about disparities between the data. Both model and remote sensing data have different characteristics, which have to be considered when interpreting differences of the measured and modelled data. Here we discuss the 

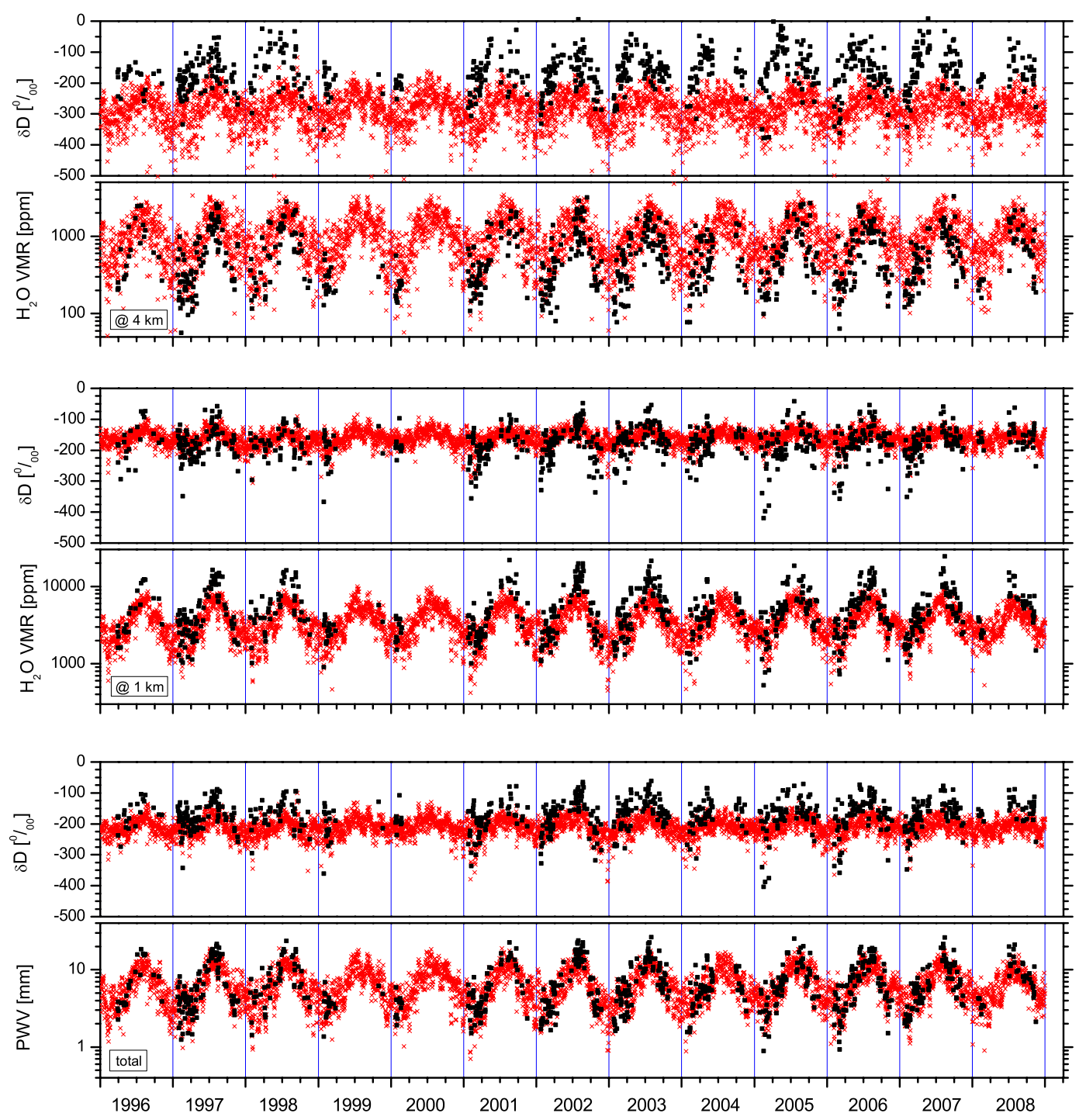

Fig. 1. Kiruna $\mathrm{H}_{2} \mathrm{O}$ and $\delta \mathrm{D}$ time series. Black squares: ground-based FTIR measurements; Red crosses: IsoGSM simulations; Panels from the bottom to the top: column integrated atmosphere, lower troposphere (altitude of $1 \mathrm{~km}$ ), middle troposphere (altitude of $4 \mathrm{~km}$ ).

differences between IsoGSM and FTIR with respect to vertical resolution, horizontal resolution, temporal resolution, and sampling frequency.

1. Vertical resolution: The vertical resolution of the FTIR $\mathrm{H}_{2} \mathrm{O}$ and $\delta \mathrm{D}$ profiles is indicated by the averaging kernels shown in Fig. 3 for typical Kiruna and Izaña measurements. Concerning $\mathrm{H}_{2} \mathrm{O}$ and defined as full width half maximum of the averaging kernels, the vertical resolution is $2 \mathrm{~km}$ in the lower troposphere, $4 \mathrm{~km}$ in the middle troposphere, and $6 \mathrm{~km}$ in the upper troposphere. The vertical resolution of the $\delta \mathrm{D}$ profiles is coarser: about $3 \mathrm{~km}$ in the lower troposphere and $6 \mathrm{~km}$ in the middle troposphere. Typical degrees of freedoms are 2.6 for $\mathrm{H}_{2} \mathrm{O}$ and 1.6 for $\delta \mathrm{D}$. Figure 3 also depicts the sum of all averaging kernels (thick solid black line), which indicates the total sensitivity of the FTIR system with respect to $\mathrm{H}_{2} \mathrm{O}$ and $\delta$ D. For Kiruna the FTIR system is sensitive up to an altitude of $7 \mathrm{~km}$ (more than $75 \%$ of the atmospheric $\mathrm{H}_{2} \mathrm{O}$ and $\delta \mathrm{D}$ variability is detected by FTIR, see curve $\Sigma_{\text {row }}$ ). For Izaña this sensitivity range is extended up to $10-11 \mathrm{~km}$. In contrast to the coarse vertical resolution of the FTIR profiles the model has better vertical resolution. For the following analyses we smooth the modelled profiles with the FTIR averaging kernels. This assures that measured and simulated profiles represent the same details of the vertical $\mathrm{H}_{2} \mathrm{O}$ and $\delta \mathrm{D}$ structures. 

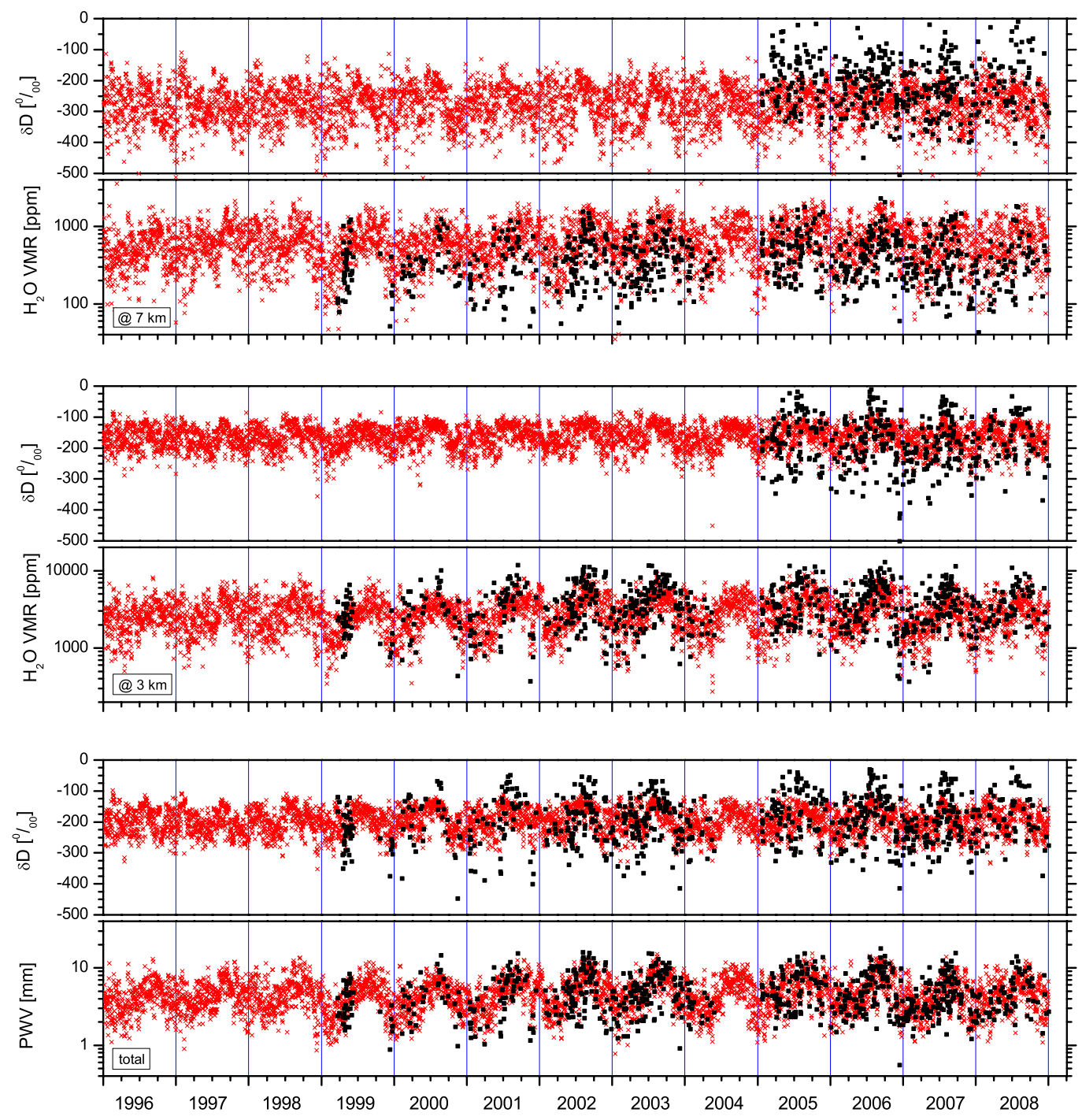

Fig. 2. Same as Fig. 1, but for Izaña and the column integrated atmosphere, the lower free troposphere (at $3 \mathrm{~km}$ ), and the middle troposphere (at $7 \mathrm{~km})$.

2. Horizontal resolution: The FTIR data represent the atmosphere along the straight line that connects the sun and the ground-based FTIR spectrometer. It is near to a point measurement. On the other hand, the vertical resolution of the model is $200 \mathrm{~km}$ and consequently the model data represent the atmosphere as averaged over a $200 \times 200 \mathrm{~km}$ area. From this point of view we expect that the FTIR data show more short-term variability than the model data. This disparity increases the scatter between measurements and simulations but averages out when contemplating long time scales.

3. Temporal resolution: The temporal extent of the FTIR measurements is in the order of minutes. The measurements are well able to detect instantaneous small scale features. On the contrary, the model's temporal output step is $6 \mathrm{~h}$ (although its time step is less than $30 \mathrm{~min}$ ). It represents atmospheric features averaged over $6 \mathrm{~h}$. This disparity will cause the FTIR data to be more variable on short time scales than the model data. As for the horizontal resolution, this disparity averages out when contemplating longer time scales.

4. Sampling frequency: The FTIR measurements are only performed for clear sky conditions and only represent the atmosphere for a short instant. On the other hand the model provides continuous data. It is representative for all atmospheric conditions. In the following we only apply model data that temporarily match with the FTIR data within $3 \mathrm{~h}$, which reduces the effects of this disparity. 

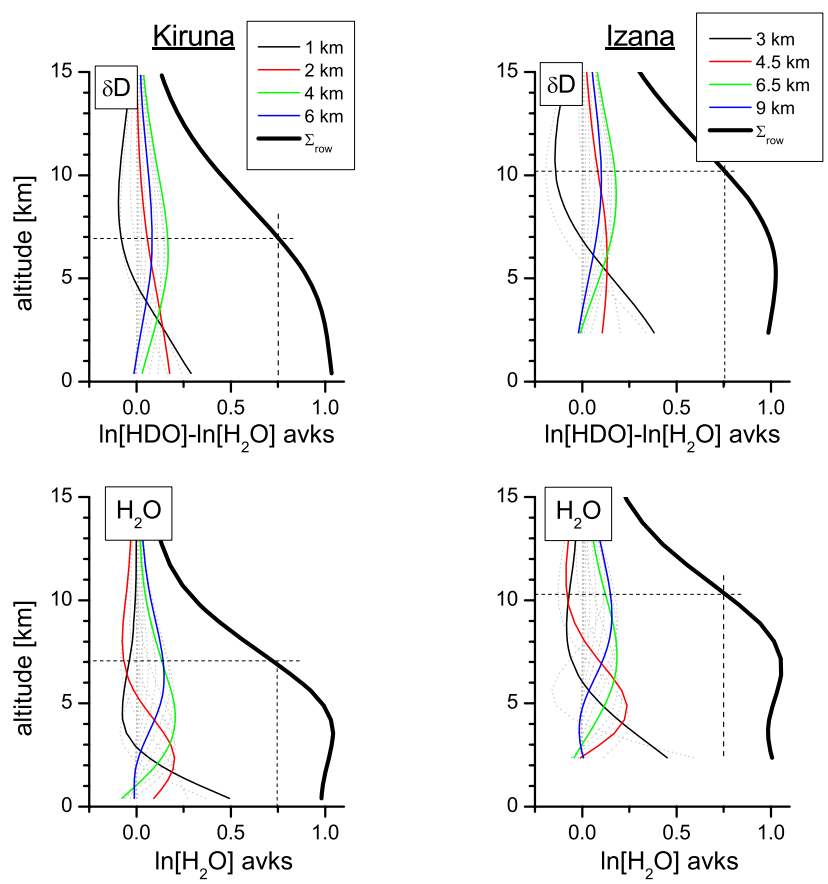

Fig. 3. FTIR Averaging kernels for $\mathrm{H}_{2} \mathrm{O}$ (bottom panels) and $\delta \mathrm{D}$ (expressed as $\ln \frac{[\mathrm{HDO}]}{\left[\mathrm{H}_{2} \mathrm{O}\right]}$, top panels). Left panels for Kiruna and right panels for Izaña.

\subsection{Statistics of the IsoGSM-FTIR differences}

In Fig. 4 we show a statistics of the comparison between daily mean values of FTIR measurements and coincident IsoGSM simulations smoothed by the FTIR averaging kernels. These statistics are based on coincidences for about 770 and 400 different days for Kiruna and Izaña, respectively. The lower panels show the mean difference and the $1 \sigma$ scatter of the difference of the $\mathrm{H}_{2} \mathrm{O}$ VMRs. The characteristic of the model-measurement difference is very similar for Kiruna and Izaña. In the lower troposphere the model underestimates and in the middle/upper troposphere the model overestimates the measured $\mathrm{H}_{2} \mathrm{O}$ VMRs. These observations are in line with the study of John and Soden (2007) who report a systematic boundary layer dry bias and a free tropospheric wet bias for a variety of different AGCMs. As grey line and area in the lower right panel we depict the statistics of the difference between Vaisala RS92 radiosonde and FTIR measurements performed simultaneously between 2005 and 2008 at Izaña (Schneider et al., 2010). It documents the quality of the FTIR $\mathrm{H}_{2} \mathrm{O}$ profiles.

The top panels of Fig. 4 depict the mean difference and $1 \sigma$ scatter between measured and simulated $\delta \mathrm{D}$ profiles. For both sites we observe a systematic difference between the IsoGSM and FTIR middle/upper tropospheric $\delta \mathrm{D}$ of about $100 \%$. This difference is larger for Kiruna as compared to Izaña. In both cases we already observe a systematic differ-
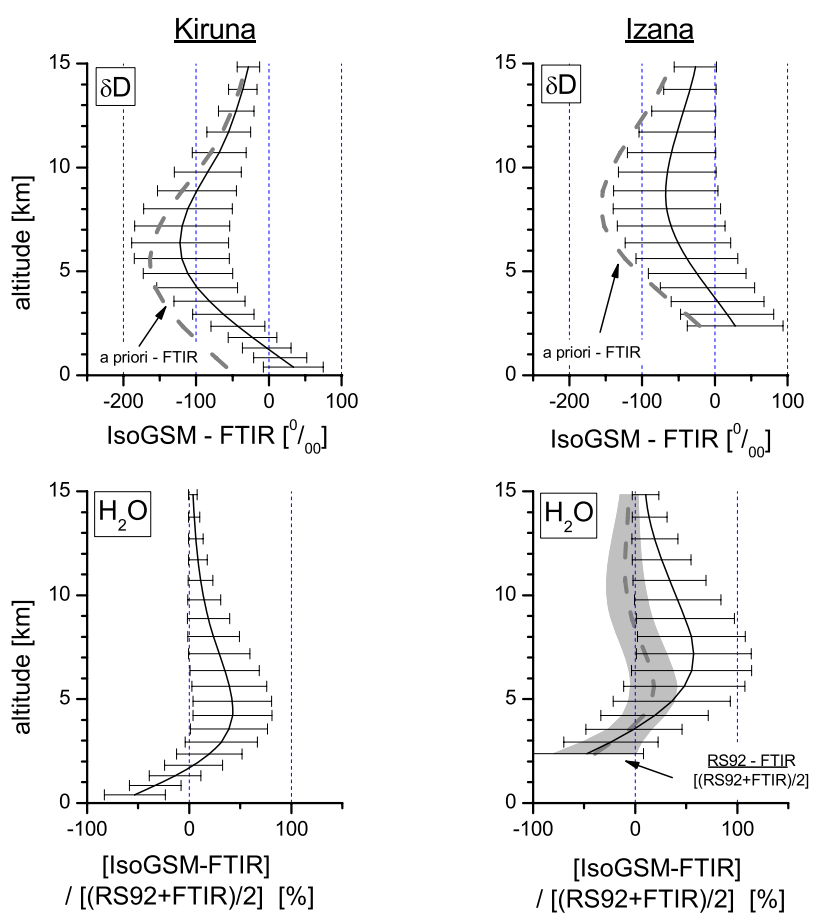

Fig. 4. Statistics for the difference between coincident FTIR profile measurements and IsoGSM profile simulations. Bottom panels: $\mathrm{H}_{2} \mathrm{O}$, top panels: $\delta \mathrm{D}$. Left panels: Kiruna, right panels: Izaña. The grey area in the right bottom panel shows the comparison between Vaisala RS92 and FTIR measurements (grey dotted line: mean; grey area: $1 \sigma$ standard deviation). The grey dotted lines in the top panels show the difference between the mean retrieved FTIR $\delta \mathrm{D}$ values and the a priori $\delta \mathrm{D}$ profile, which has been constructed from in-situ $\delta \mathrm{D}$ measurements.

ence between FTIR and $\delta \mathrm{D}$ climatologies, which are constructed from a variety of different in-situ measurements (Taylor , 1972; Ehhalt, 1974; Zahn, 2001) and applied as a priori $\delta \mathrm{D}$ profiles for the FTIR retrieval. The mean differences of the FTIR $\delta \mathrm{D}$ profiles and the in-situ profiles are depicted as grey dashed line in the top panels of Fig. 4. The FTIR systematically underestimates the tropospheric HDO depletion measured by the in-situ experiments. However, the in-situ data are collected at sites and times that differ from the FTIR measurements and consequently this comparison is subject to large uncertainties. On the other hand an error of about $2.5 \%$ in the spectroscopic pressure broadening coefficients would cause an systematic middle/upper tropospheric $\delta \mathrm{D}$ error of $100 \%$ (see Table 1 ). We think that an important part of the systematic difference between the FTIR and insitu profiles is due to a bias in the FTIR data.

The scatter between the FTIR and IsoGSM $\delta \mathrm{D}$ is about $50 \%$ for the lower troposphere in Kiruna and about $80 \%$ for the middle troposphere in Kiruna and for the lower and middle troposphere in Izaña. This is more than what we 
estimated for the FTIR $\delta$ D precision, which is $15 \%$ o for the lower troposphere and 30\% for the middle troposphere (for an assumed $1 \%$ uncertainty in the pressure broadening parameter, see Table 1). We think that uncertainties in the FTIR data explain a part of the observed scatter but not all. Instead the scatter may also reveal disparities between the FTIR and IsoGSM data (see discussion in Sect. 3.3) or differences between the real atmosphere and the IsoGSM simulations. In the following sections we examine in detail the model and measurement differences and to what extent the modelled and measured variability reflects some complexities of the water cycle.

\section{Scientific interpretation of the time series}

In this section we perform a detailed analysis of the measured time series and the modelled time series for both, nudged and free run IsoGSM simulations.

\subsection{The method}

Figures 1 and 2 show that the annual cycles are the dominating signatures in the tropospheric $\mathrm{H}_{2} \mathrm{O}$ and $\delta \mathrm{D}$ time series. The annual cycles are superimposed on short time scale variability and possible inter-annual variability. The objective of the data analysis method is to compare measurement and model on different time scales and to interpret the variability. Therefore, we construct a function $F(t)$, that consists of several parameter functions that we assume to be the major variability sources:

$$
\begin{aligned}
F(t)= & f_{0}+f_{1} \cos 2 \pi t+f_{2} \sin 2 \pi t \\
& +f_{3} \cos 4 \pi t+f_{4} \sin 4 \pi t \\
& +f_{5} \cos 6 \pi t+f_{6} \sin 6 \pi t \\
& +f_{\mathrm{p}} F_{\mathrm{path}}(t) \\
& +f_{\mathrm{i} 1} F_{\text {index } 2}(t)+f_{\mathrm{i} 2} F_{\text {index } 2}(t) \\
& +f_{\mathrm{s}} F_{\text {sens }}(t)
\end{aligned}
$$

The different parameter functions are then fitted simultaneously - in a least squares sense - to the measured and modelled time series. By a bootstrap method (e.g. Gardiner et al., 2008) we can estimate the significance of the correlations between the different parameter functions and the dataset.

The first three lines on the right hand side of Eq. (1) account for the annual cycle, which is modelled in terms of a Fourier series where $t$ is measured in years, and $f_{0}$ to $f_{6}$ are the parameters of the Fourier series. We consider frequencies up to 3 year $^{-1}$. This turns out to be sufficient and yields very robust fitting results.

The fourth line of Eq. (1) accounts for the correlation between $\mathrm{H}_{2} \mathrm{O}$ and $\delta \mathrm{D}$. Assuming Rayleigh distillation, changes of water vapour amounts $\left(d \ln \left[\mathrm{H}_{2} \mathrm{O}\right]\right)$ and changes of $\delta \mathrm{D}$ in

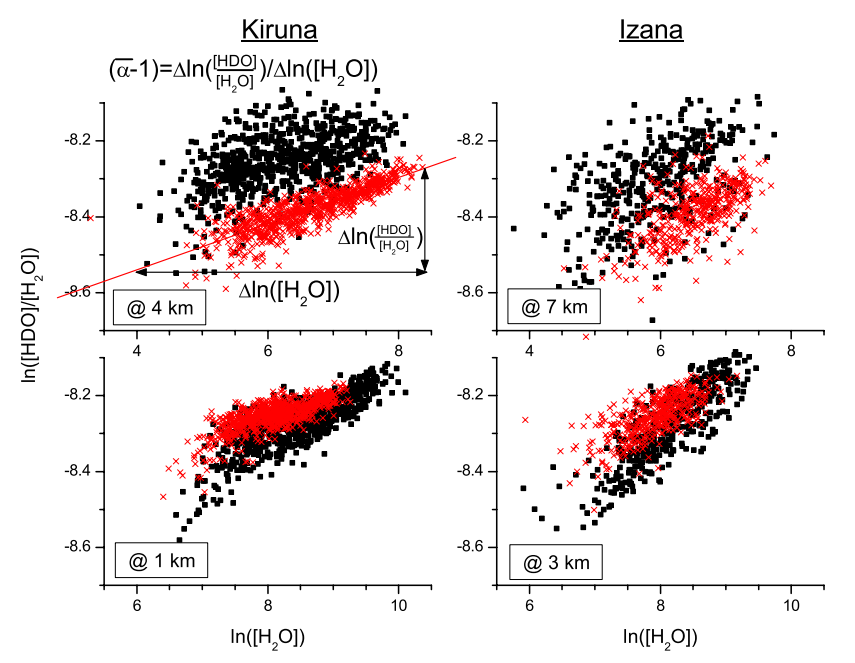

Fig. 5. Correlation between $\ln \left[\mathrm{H}_{2} \mathrm{O}\right]$ amounts and the $\delta \mathrm{D}$ values (expressed as $\ln \frac{[\mathrm{HDO}]}{\left[\mathrm{H}_{2} \mathrm{O}\right]}$ ), for the lower and middle troposphere (bottom and top panels, respectively). Left panel: for Kiruna; Right panel: for Izaña. Black solid squares represent FTIR measurements and red crosses IsoGSM simulations.

the vapour phase (represented by $d \ln \frac{[\mathrm{HDO}]}{\left[\mathrm{H}_{2} \mathrm{O}\right]}$ ) are connected via the following relation (e.g. Dessler and Sherwood, 2003):

$(\alpha-1) d \ln \left[\mathrm{H}_{2} \mathrm{O}\right]=d \ln \frac{[\mathrm{HDO}]}{\left[\mathrm{H}_{2} \mathrm{O}\right]}$

whereby $\alpha$ is the equilibrium fractionation coefficient (van Hook , 1968). Since $\alpha$ depends on temperature and since Rayleigh distillation is only one of several different fractionation processes, the relation between $\ln \left[\mathrm{H}_{2} \mathrm{O}\right]$ and $\ln \frac{[\mathrm{HDO}]}{\left[\mathrm{H}_{2} \mathrm{O}\right]}$ depends on the history of the analysed airmass and varies from day-to-day. Nevertheless, as shown in Fig. 5, there is a strong correlation between $\ln \left[\mathrm{H}_{2} \mathrm{O}\right]$ and $\ln \left[\frac{\mathrm{HDO}]}{\left[\mathrm{H}_{2} \mathrm{O}\right]}\right.$ concerning both the model and the measurement. The slope of the corresponding regression lines $(\bar{\alpha}-1)=\Delta \ln \frac{[\mathrm{HDO}]}{\left[\mathrm{H}_{2} \mathrm{O}\right]} / \Delta\left[\mathrm{H}_{2} \mathrm{O}\right]$ is a measure for the typical water transport pathways. Analysing the slope $(\bar{\alpha}-1)$ allows investigating the importance of different hydrological processes (similar to analysing the $\delta \mathrm{D}$ $\mathrm{H}_{2} \mathrm{O}$ scatter plots of Worden et al., 2007). We estimate $(\bar{\alpha}-1)$ by fitting a function $F_{\text {path }}(t)$ to the $\delta \mathrm{D}$ time series $\left((\bar{\alpha}-1)=f_{\mathrm{p}}\right)$. The function $F_{\mathrm{path}}(t)$ is a time series of the variability in $\ln \left[\mathrm{H}_{2} \mathrm{O}\right]$. It describes by how much the actual logarithm of the $\mathrm{H}_{2} \mathrm{O}$ amount $\left(\ln \left[\mathrm{H}_{2} \mathrm{O}\right](t)\right)$ deviates from its mean value $\left(\overline{\ln \left[\mathrm{H}_{2} \mathrm{O}\right]}\right)$. Therein, we have to consider that the FTIR system can observe much finer $\mathrm{H}_{2} \mathrm{O}$ than $\delta$ D structures (see Fig. 3) and construct a function $F_{\text {path }}(t)$ applying $\mathrm{H}_{2} \mathrm{O}$ data smoothed by the $\delta \mathrm{D}$ averaging kernels.

The fifth line of Eq. (1) contains the time series of climatological indices, that are assumed to affect the transport of water through the atmosphere. In order to get stable fitting results the applied indices must be uncorrelated. For each site we fit two different indices: a first index describing patterns 

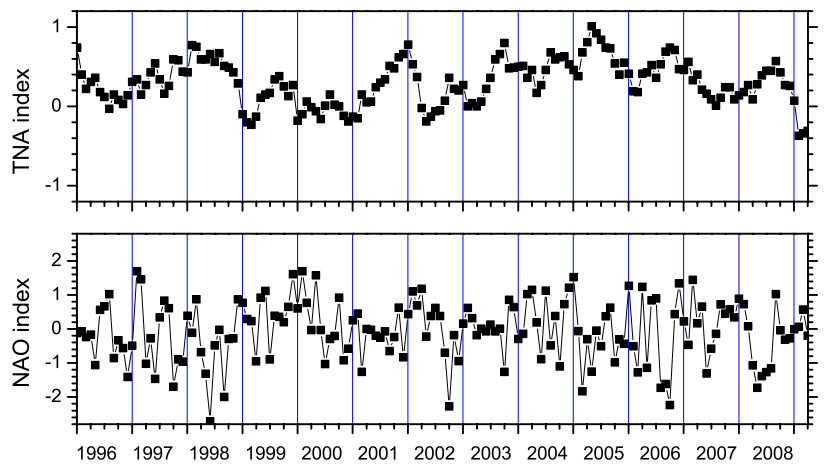

Fig. 6. Time series of the TNA (Tropical Northern Atlantic) and the NAO (North Atlantic Oscillation) index.

of atmospheric circulation variability (the Arctic Oscillation (AO) index for Kiruna and the Northern Atlantic Oscillation (NAO) index for Izaña), and a second index describing SST anomalies (the Atlantic Multidecadal Oscillation (AMO) index for Kiruna and the Tropical Northern Atlantic (TNA) index for Izaña). The indices have been adopted from the web page of the Earth System Research Laboratory (ESRL) of the National Oceanic and Atmospheric Administration (NOAA): http://www.esrl.noaa.gov/psd/data/climateindices/. Figure 6 depicts as an example the two functions $F_{\text {index } 1}(t)$ and $F_{\text {index } 2}(t)$ fitted to the Izaña time series: the NAO index, and the TNA index.

The sixth line of Eq. (1), accounts for the variation of the FTIR system's sensitivity. $F_{\text {sens }}(t)$ is a time series of the altitude specific sensitivity value (thick black line, $\Sigma_{\text {row }}$, of Fig. 3). The simultaneous fit of $F_{\text {sens }}(t)$ reduces the impact of systematic errors (e.g. due to spectroscopic parameters) on the data analysis.

As described by Eq. (1) we fit 10 parameter functions to the $\mathrm{H}_{2} \mathrm{O}$ time series and 11 parameter functions to the $\delta \mathrm{D}$ time series (when including $F_{\text {path }}(t)$ ). In the case of Kiruna the time series consist of 1700 individual FTIR observations made on 770 different days between 1996 and 2008. At Izaña so far only the IFS $120 / 5 \mathrm{HR}$ data fulfill the stringent quality criterion required for $\delta \mathrm{D}$ profile observations. In this case we analyse the time series between 2005 and 2008 only. It consists of more than 850 individual FTIR observations made on 400 different days.

\subsection{Typical water transport pathways}

Figure 7 depicts the slopes $(\bar{\alpha}-1)$ determined by our multiregression method (by fitting $F_{\text {path }}(t)$ to the $\delta \mathrm{D}$ time series). As aforementioned $(\bar{\alpha}-1)$ contains information about the mean situation (typically involved water transport pathways). Black, red, and green curves represent the results from the measurements, the nudged model run, and the free model run, respectively. The hatched area around the curves in-

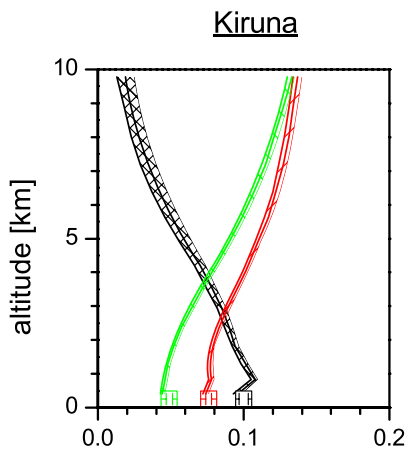

$(\bar{\alpha}-1)$

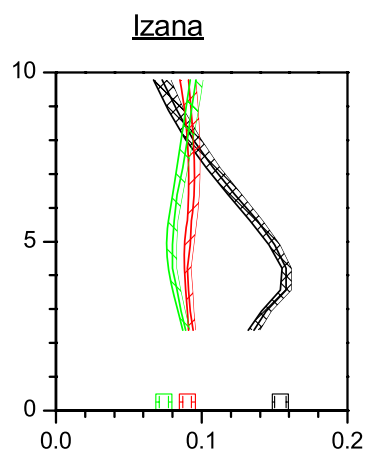

$(\bar{\alpha}-1)$

Fig. 7. Slope $(\bar{\alpha}-1)$ throughout the troposphere. Left panel for Kiruna and right panel for Izaña. Black, red, and green lines represent the FTIR measurements, the nudged model run, and the free model run, the hatched areas represent the $1 \sigma$ significance intervals. The open squares upon the bottom $\mathrm{x}$-axis represent the slope $(\bar{\alpha}-1)$ for the column integrated data.

dicate the $1 \sigma$ (i.e. 67\%) significance area. There are significant differences between measurement and model. At both sites $(\bar{\alpha}-1)$ as derived from the measurement decreases with height, whereas for the models it tends to increase with height.

A part of these significant differences might be caused by uncertainties in the FTIR data: e.g., a correlation between the measured $\mathrm{H}_{2} \mathrm{O}$ and the $\delta \mathrm{D}$ error would cause a systematic error in the measured $(\bar{\alpha}-1)$. However, fitting function $F_{\text {sens }}(t)$ minimises a possible correlation between the measured $\mathrm{H}_{2} \mathrm{O}$ and a $\delta \mathrm{D}$ error and we think that most of the observed differences in $(\bar{\alpha}-1)$ is due to a model error. The supposed model error is not reduced by nudging the model towards the dynamic fields of reanalysis data, which allows excluding a wrong model dynamics as an error source. Instead an incorrect modelling of hydrological processes, e.g., underestimating the importance of rain evaporation or errors in the parameterisation of certain processes (sub-scale mixing, inner-cloud processes, convection, etc.), might play a role. It is known that global climate models have problems in reproducing the vertical large scale distribution of tropospheric humidity (John and Soden, 2007). Our simultaneous measurements of tropospheric tropospheric $\mathrm{H}_{2} \mathrm{O}$ and $\delta \mathrm{D}$ profiles might help to constrain these climate model deficits, which is, however, outside the scope of this paper.

In the following we analyse all $\delta \mathrm{D}$ time series twice by two different fits to the model function $F(t)$ of Eq. (1): a first without and a second with fitting $F_{\text {path }}(t)$. We call the $\delta \mathrm{D}$ values resulting from an analysis including an $F_{\text {path }}(t)$ fit the $\delta \mathrm{D}^{\prime}$ values. By producing the $\delta \mathrm{D}^{\prime}$ values we partly remove the aforementioned systematic model deficits (and/or measurement errors). Furthermore, the $\delta \mathrm{D}^{\prime}$ values are independent 
from the $\mathrm{H}_{2} \mathrm{O}$ values and thus reveal the actual gain of information by measuring $\mathrm{HDO}$ in addition to $\mathrm{H}_{2} \mathrm{O}$.

\subsection{Annual cycles}

Figure 8 depicts the annual cycles as derived for Kiruna by fitting function $F(t)$ to the dataset. There is a good agreement between the annual evolution of modelled (red line for nudged run, green line for free run) and measured (black line) $\mathrm{H}_{2} \mathrm{O}$. Model and measurement indicate a pronounced $\mathrm{H}_{2} \mathrm{O}$ maximum in July/August for PWV, the lower, and the middle troposphere. As already shown in Fig. 4, the modelled middle tropospheric water vapour amounts are systematically larger than the measured amounts. This difference is significantly larger than the systematic uncertainty of the FTIR $\mathrm{H}_{2} \mathrm{O}$ data (indicated by the error bars) and reveals the aforementioned wet bias in AGCMs (e.g., John and Soden, 2007). Concerning column integrated and lower tropospheric $\delta \mathrm{D}$ both model and measurements reproduce the maximum in summer, but the amplitude (peak-to-peak difference between summer and winter) is larger in the measured than in the modelled cycle. These amplitudes are slightly reduced for $\delta \mathrm{D}^{\prime}$ indicating that the water vapour transport pathways to Kiruna's lower troposphere are during the whole year very similar: the water vapour evaporates from the Atlantic Ocean and is transported efficiently to northern Scandinavia. The situation changes completely in the middle troposphere where the differences between modelled and measured $\delta \mathrm{D}$ are very large. A part of the annual mean difference of about $80 \%$ may be explained by systematic FTIR errors (the error bars at mid February indicate the systematic uncertainty of the FTIR data according to Table 1). In addition there are large differences in the intra-annual variability. While the FTIR observes a $\delta \mathrm{D}$ maximum in April/May and enhanced values until October, the IsoGSM maximum is confined within July and August in parallel to the $\mathrm{H}_{2} \mathrm{O}$ maximum. The large amplitude in the measured $\delta \mathrm{D}^{\prime}$ cycle suggests large intra-annual variability in the water vapour transport pathways to Kiruna's middle troposphere and/or large intra-annual variability in the involved fractionation processes. Between spring (high $\delta \mathrm{D}^{\prime}$ values) and autumn (low $\delta \mathrm{D}^{\prime}$ values) the transport processes and/or involved fractionation processes differ systematically. This suggests different water source region for spring and autumn, a situation that is not captured by the model.

The annual cycles for Izaña are shown in Fig. 9. For $\mathrm{H}_{2} \mathrm{O}$ the agreement between nudged run model (red line) and measurement (black line) is similar to Kiruna: $\mathrm{H}_{2} \mathrm{O}$ cycles agree well throughout the troposphere (besides the model's middle/upper tropospheric wet bias). Concerning $\delta \mathrm{D}$, the agreement is satisfactory but with a slightly larger amplitude in the measured than in the modelled cycle. This difference in the amplitude is widely eliminated for $\delta \mathrm{D}^{\prime}$. The annual mean systematic difference can be partly explained by systematic errors in the FTIR data (estimated systematic errors are indi-
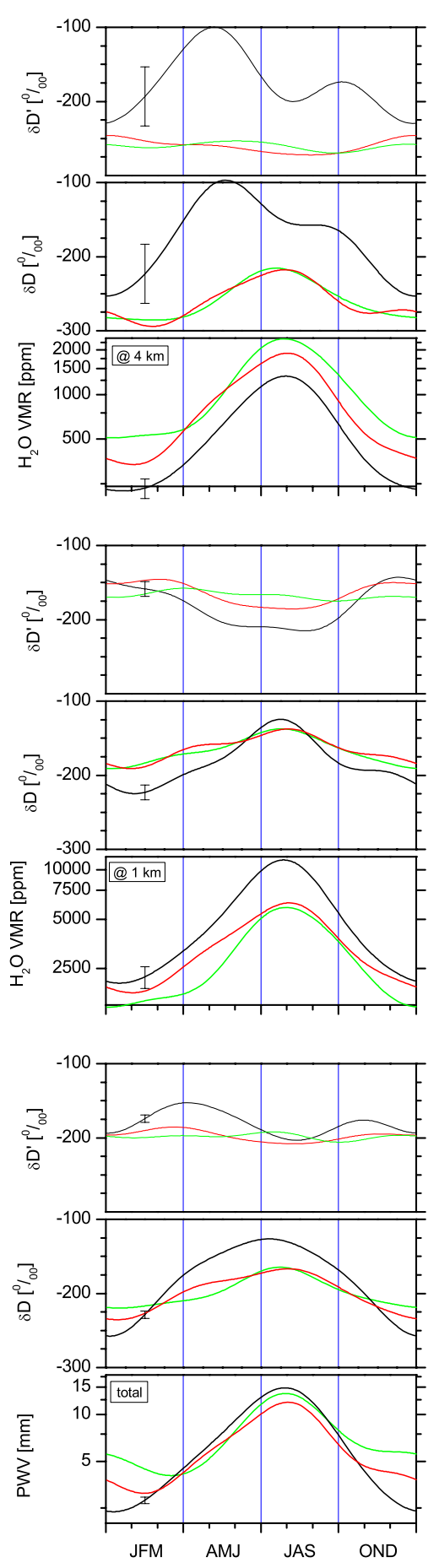

Fig. 8. Annual cycles for $\mathrm{H}_{2} \mathrm{O}, \delta \mathrm{D}$, and $\delta \mathrm{D}^{\prime}$ for Kiruna. Panels from the bottom to the top: column integrated atmosphere, lower free troposphere, and middle troposphere. Black line: FTIR, red line: nudged run IsoGSM, green line: free run IsoGSM. The error bars at mid February indicate the estimated systematic error of the FTIR data. 

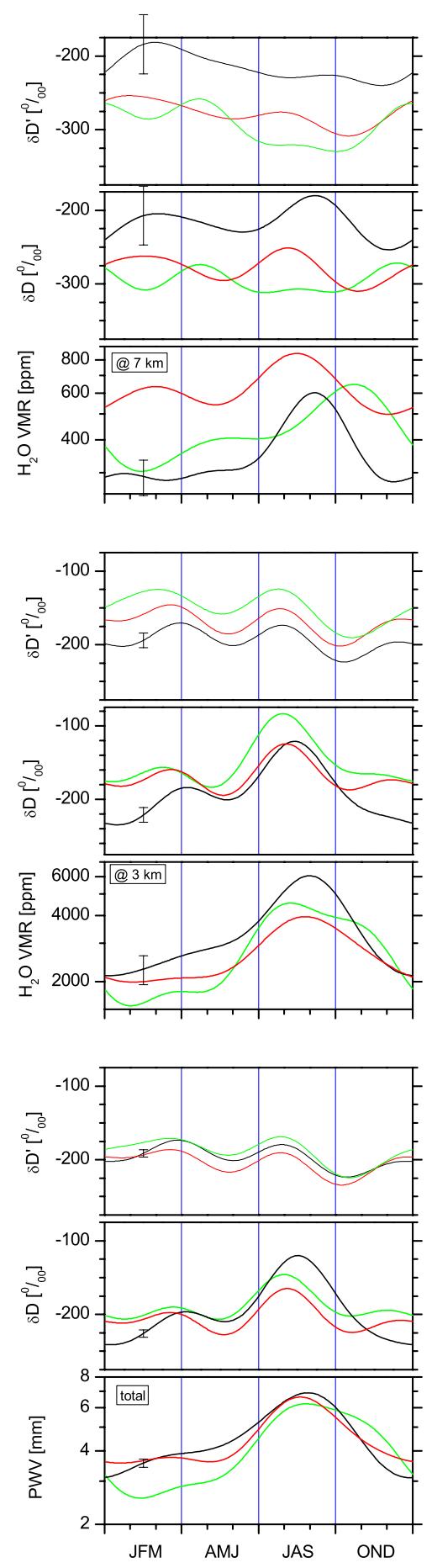

Fig. 9. Same as Fig. 8, but for the subtropical site of Izaña.

cated as error bars). It is very interesting that model and measurement reveal two maxima: a first one in March/April and a second one in August. This August maximum is a surprise since the Hadley cell is intense over the northern hemispheric subtropics until the end of October and correspondingly a minimum in $\delta \mathrm{D}$ and $\delta \mathrm{D}^{\prime}$ should be expected throughout the summer. However at Izaña, due to its location close to the African west coast, we have to deal with a particular feature: the combination of the African mid-tropospheric high, centered typically in south western Algeria at $25^{\circ} \mathrm{N}$ and of the African Easterly Jet, which develops in northern hemispheric summer at $15^{\circ} \mathrm{N}$ between $30^{\circ} \mathrm{W}$ and $20^{\circ} \mathrm{E}$, favours the transport of humid lower tropospheric air into the Canarian middle troposphere (Cook, 1999; Chen, 2006). The free run model (green line) is not able to capture this regional feature. It simulates summer troposphere dominated by the Hadley circulation with middle/upper tropospheric $\mathrm{H}_{2} \mathrm{O}, \delta \mathrm{D}$, and $\delta \mathrm{D}^{\prime}$ values being relatively low during the entire summer.

As a detail we observe a small time shift of about 12 months in the the August/September maxima between nudged run model and measurement. This might be due to a small scale local feature that cannot be captured by the model: continuous heating of the Island of Tenerife during summer may induce small scale circulations above the Island. This circulation is most pronounced at the end of summer and transports very effectively low tropospheric humid air to higher altitudes.

\subsection{Short-term variability and anomalies}

In this subsection we compare measured and modelled data after removing the annual cycle, i.e. we contemplate deseasonalised data. The $\mathrm{H}_{2} \mathrm{O}$ time series are deseasonalised by dividing through the annual cycle and the $\delta \mathrm{D}$ time series by subducting the annual cycle. Deseasonalising allows a validation of the model on different time scales independent from the systematic model-measurement differences presented in Figs. 8 and 9.

Figure 10 presents the deseasonalised variances of measurement and model. For Kiruna and $\mathrm{H}_{2} \mathrm{O}$ there is an excellent agreement between the model and the measurements. In Izaña FTIR $\mathrm{H}_{2} \mathrm{O}$ data show more scatter than the nudged run model data, whereby the free run model agrees well within the measurement uncertainties. Concerning $\delta \mathrm{D}$ we observe, similar to $\mathrm{H}_{2} \mathrm{O}$, that the agreement is better for Kiruna than for Izaña and that in Izaña the variance of the free run model data agrees better with the measured variance than the nudged run variance. When removing the correlation between $\mathrm{H}_{2} \mathrm{O}$ and $\delta \mathrm{D}$, i.e. when contemplating $\delta \mathrm{D}^{\prime}$, we naturally observe a reduced deseasonalised variance, but the difference between measurement and model remains. For both sites the measured $\delta \mathrm{D}^{\prime}$ variance is significantly larger than the modelled variance. The error bars added to the measured variance profiles represent the error variance according to the estimations listed in Table 1 . For $\delta \mathrm{D}$ these error bars are much smaller than the difference between the measured and the modelled variances, meaning that measurement errors alone cannot explain the increased variability in the FTIR $\delta$ D data. Instead the reduced temporal and horizontal resolution of the model in comparison to the measurements 

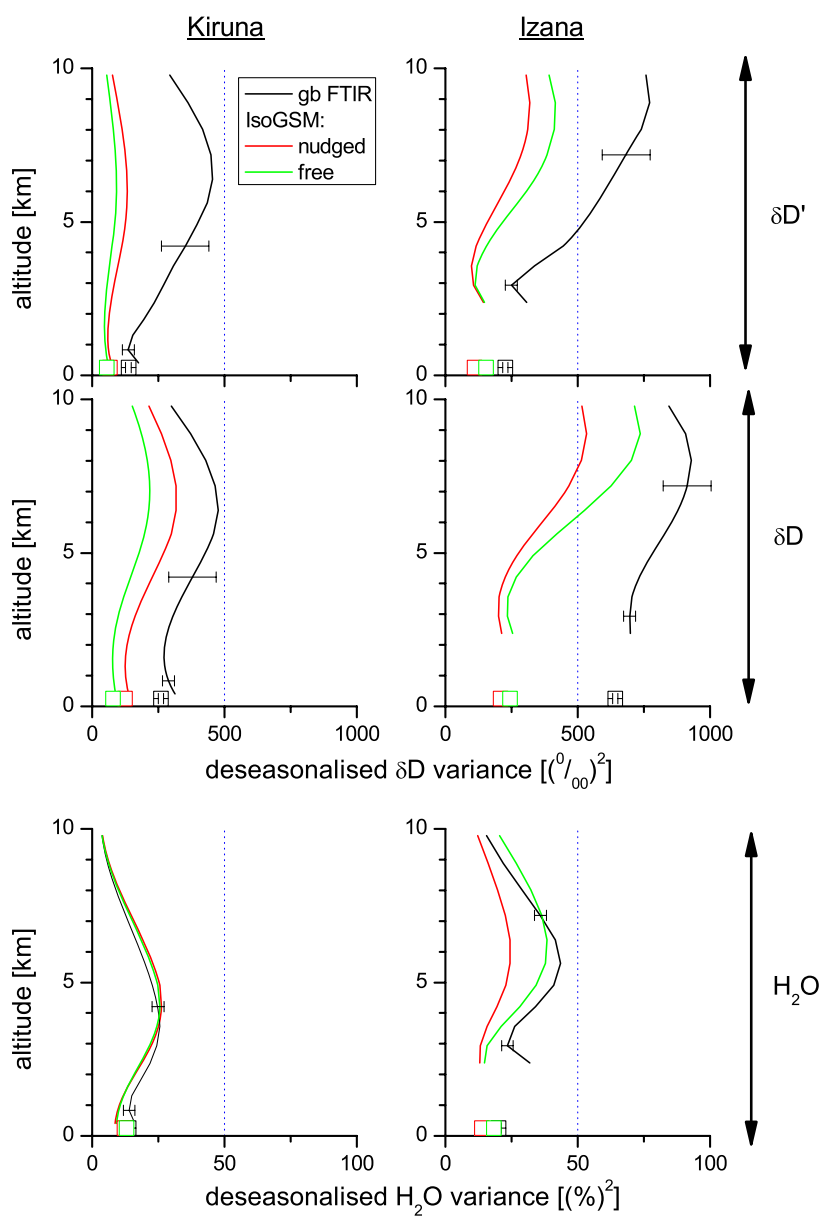

Fig. 10. Profiles of the variance of the deseasonalised daily mean data. Left panels for Kiruna and right panels for Izaña. The panels from the bottom to the top present data for $\mathrm{H}_{2} \mathrm{O}, \delta \mathrm{D}$, and $\delta \mathrm{D}^{\prime}$. The black, red, and green lines represent the FTIR measurement, nudged model run data, and free model run data, respectively. The error bars represent the estimated error variance for the lower and middle/upper troposphere. The open squares and error bars upon the bottom $\mathrm{x}$-axis represent the variances for the column integrated data.

(see Sect. 3.3) and an underestimation of the real atmospheric variability by the model must be the main reasons for the relatively low scatter in the modelled $\delta \mathrm{D}$.

In the following we examine the correlation between the measured and modelled variability. Figure 11 shows profiles of the coefficient of determination $\left(R^{2}\right)$ for deseasonalised daily mean and quarterly mean variability. In the case of a linear correlation $R^{2}$ is the portion of the variance of the measured data that can be explained by the modelled data. An $R^{2}$ of 1 means that the model explains all the variance in the measured $\mathrm{H}_{2} \mathrm{O}$ or $\delta \mathrm{D}$ data, and an $R^{2}$ of 0 means that model and measurement are completely uncorrelated. The red line and hatched area represent the $R^{2}$ values and the $1 \sigma$ confi- dence interval for the nudged run comparison and the green line and hatched area the results for the free run comparison. Concerning the nudged run data all correlation are significant at a $95 \%$ confidence level. In the lower troposphere the nudged model explains $70 \%$ of the measured $\mathrm{H}_{2} \mathrm{O}$ variances, and in the middle/upper troposphere still $50 \%$. These values generally increase when averaging over longer time scales, since such averaging reduces the scatter that is introduced by differences in the horizontal and temporal resolution between model and measurements (see discussion of Sect. 3.3). The day-to-day scatter is determined by synoptic processes which cannot be captured by the free run model. A moderate correlation between the measurement and the free run model is only found when averaging over longer time scale. Concerning $\delta \mathrm{D}$ and the nudged model we achieve a lower tropospheric $R^{2}$ value of $50 \%$ for daily mean data and of $60 \%$ for quarterly mean data. At higher altitudes the correlation is rather weak. For $\delta \mathrm{D}^{\prime}$ the correlation is significantly stronger, since the $\delta \mathrm{D}^{\prime}$ comparison accounts for most of the synoptic and small scale variability $\left(\delta \mathrm{D}^{\prime}\right.$ data are corrected by the $\mathrm{H}_{2} \mathrm{O}$ variability, which removes most of the synoptic scale variability). Then even the free run data follow the measured day-to-day scatter (lower tropospheric $R^{2}$ of $25 \%$ ).

The nudged model is well able to reproduce the synoptic variations which allows us to compare individual days and perform a very robust validation study. The good agreement in measured and modelled day-to-day variability during more than 13 years robustly documents that the FTIR data are of reasonable quality. On the other hand the free run model is not able to reproduce synoptic short-term variability and comparisons of individual measurements are not meaningful. With non-nudged simulation data, we can only compare statistical information like mean values (Figs. 8 and 9) and variances (Fig. 10). Validation studies based on such comparisons are much less informative.

Figure 12 shows the performance of the model in the subtropical atmosphere of Izaña. Generally the correlations are poorer than for Kiruna (e.g., at Izaña $R^{2}$ values for daily mean data are all below $30 \%$, whereas at Kiruna $75 \%$ are achieved). Correlating Izaña's FTIR $\mathrm{H}_{2} \mathrm{O}$ amounts with corresponding Vaisala RS92 radiosonde amounts yield $R^{2}$ values of about $95 \%$, which demonstrates that the relatively poor FTIR-IsoGSM correlations at Izaña are due to incorrect model data. While at Kiruna the situation is rather uniform during the whole year, the Izaña atmosphere is affected by two very distinct atmospheric patterns, the Hadley circulation, which prevails in summer, and the westerlies, which are important in winter. It seems that the model has problems capturing the associated temporal and spatial inhomogeneities. Furthermore, the Izaña measurements represent exclusively altitudes above $2.4 \mathrm{~km}$, where AGCM humidity simulations are known to be particularly strong wet-biased. 


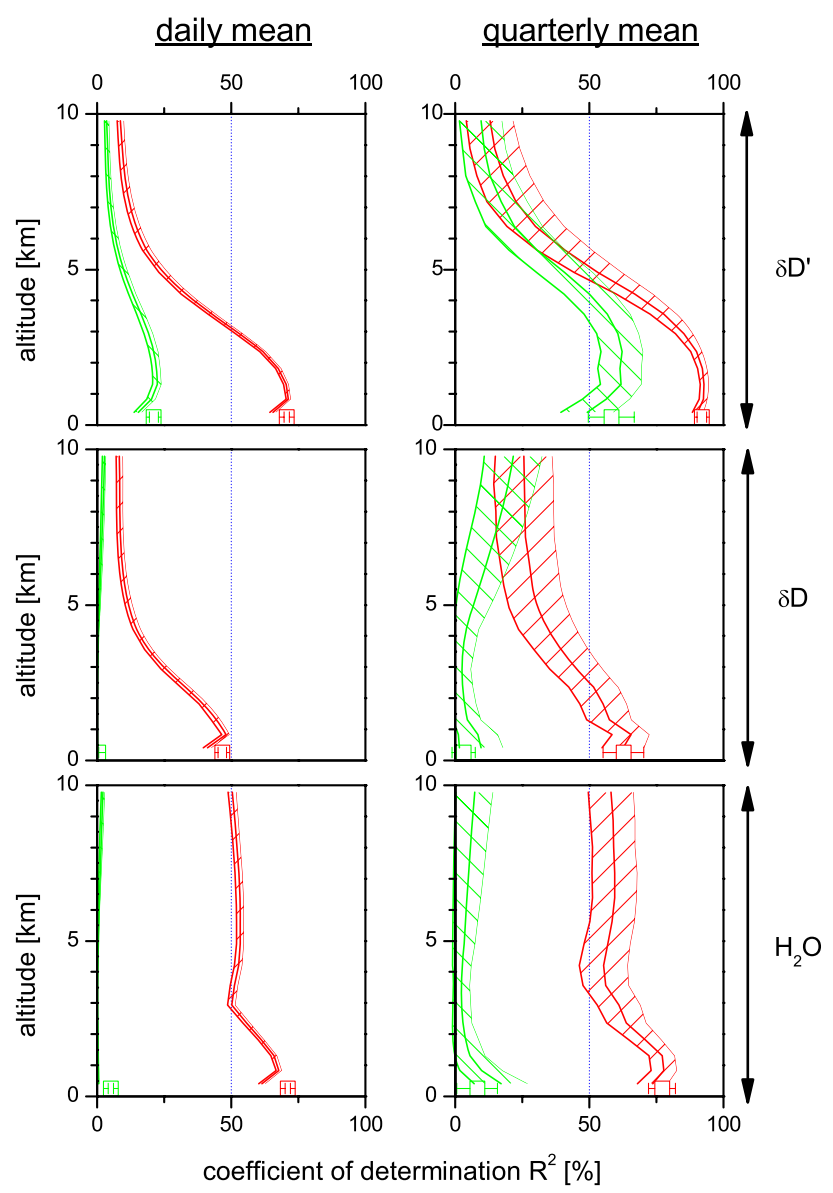

Fig. 11. Profiles of the coefficients of determination $R^{2}$ between deseasonalised FTIR and IsoGSM data of Kiruna. From the bottom to the top: $\mathrm{H}_{2} \mathrm{O}\left(\mathrm{H}_{2} \mathrm{O}\right.$ variability expressed as $\left.\ln \left[\mathrm{H}_{2} \mathrm{O}\right]\right), \delta \mathrm{D}$, and $\delta \mathrm{D}^{\prime}\left(\delta \mathrm{D}\right.$ and $\delta \mathrm{D}^{\prime}$ variability expressed as $\left.\ln \frac{[\mathrm{HDO}]}{\left[\mathrm{H}_{2} \mathrm{O}\right]}\right)$. Left: daily mean data, right: quarterly mean data. Red curve for nudged and green curve for free run IsoGSM (hatched area represents the $1 \sigma$ significance intervals). The open squares and error bars upon the bottom x-axis represent $R^{2}$ and $1 \sigma$ significance interval for column integrated data.

\subsection{Large-scale climate patterns}

In this subsection we investigate if the anomalies of the $\mathrm{H}_{2} \mathrm{O}$ and $\delta \mathrm{D}$ profiles - represented by the deseasonalised data are connected to atmospheric and oceanic large scale patterns. Therefore, we study the importance of the functions $F_{\text {index } 1}$ and $F_{\text {index } 2}$ of Eq. (1). For Kiruna we construct functions which contain the indices of the Arctic Oscillation (AO) and of the Atlantic Multidecadal Oscillation (AMO). The AO index describes $1000 \mathrm{mb}$ height anomalies north of $20^{\circ} \mathrm{N}$. It represents large scale atmospheric anomalies of the Northern Hemisphere. The AMO index is calculated from Atlantic SST anomalies north of the Equator and is representative for the oceanic anomalies in the northern Atlantic. Figure 13

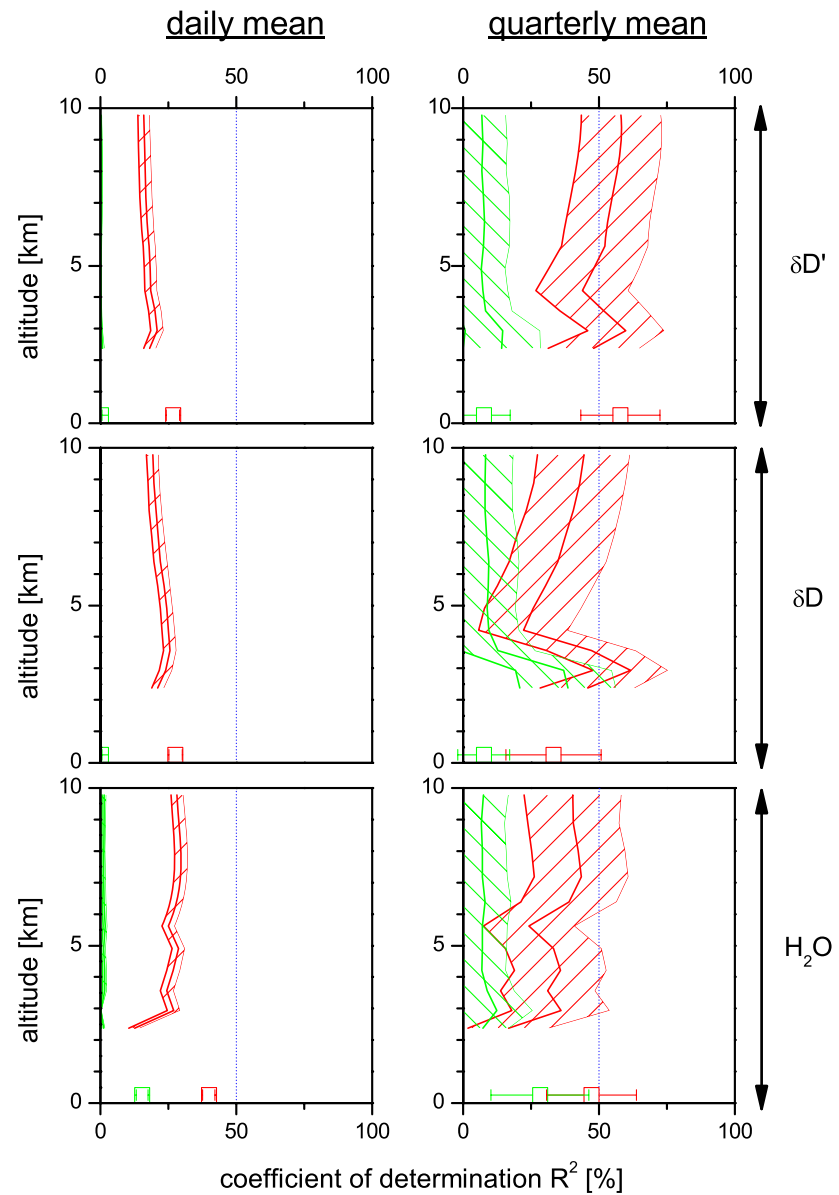

Fig. 12. Same as Fig. 11 but for Izaña.

shows the coefficient of determination $R^{2}$ (multiplied with the sign of the slope of the linear regression line) for the correlation between measured and modelled $\mathrm{H}_{2} \mathrm{O}, \delta \mathrm{D}$, and $\delta \mathrm{D}^{\prime}$ quarterly mean anomalies and the $\mathrm{AO}$ and $\mathrm{AMO}$ indices at Kiruna. We find that both $\mathrm{H}_{2} \mathrm{O}$ and $\delta \mathrm{D}$ anomalies are positively correlated with the AO index (see left panels). The correlation is particulary strong for the lower troposphere, where about $30 \%$ of the measured (black curves) and nudged model run anomalies (red curves) in $\mathrm{H}_{2} \mathrm{O}$ and $\delta \mathrm{D}$ can be explained by the $\mathrm{AO}$ index. The hatched area in the panels represent the $1 \sigma(66 \%)$ significance intervals and demonstrate that the correlations are highly significant. The green curves show the situation for the free model run. In this case we also observe some correlation for lower tropospheric $\mathrm{H}_{2} \mathrm{O}$ and $\delta \mathrm{D}$, however, the slope of the linear regression line has the opposite sign if compared to the FTIR measurements and the nudged run simulations: the free run model is not able to correctly capture the connection between the Arctic Oscillation and Kiruna's lower tropospheric water vapour. For $\delta \mathrm{D}^{\prime}$ the correlation is still strong, which means that the $\mathrm{AO}$ index is mainly correlated with atypical water vapour transport pathways. The nudged model as well as the measurement 


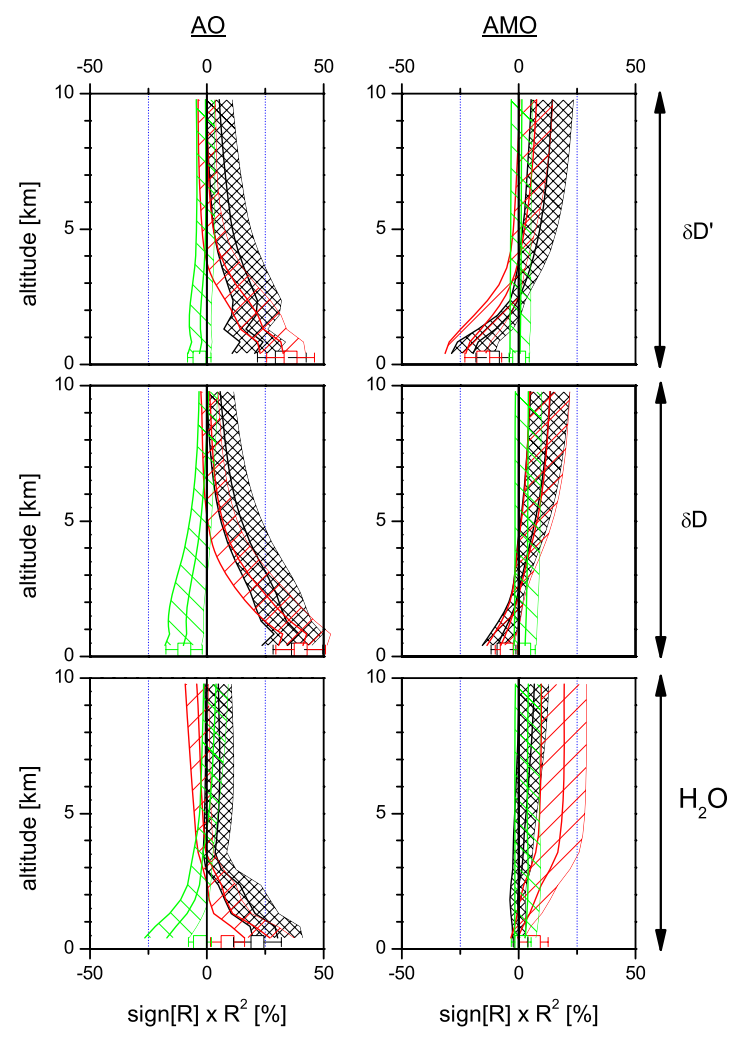

Fig. 13. Influence of the AO and the AMO index on Kiruna's troposphere: vertical profiles of the coefficients of determination $R^{2}$ between quarterly mean FTIR and IsoGSM data, on the one hand, and the AO and AMO index, on the other hand. Left panels: correlation with $\mathrm{AO}$ index; right panels: correlations with $\mathrm{AMO}$ index; panels from bottom to top: correlations with $\mathrm{H}_{2} \mathrm{O}\left(\mathrm{H}_{2} \mathrm{O}\right.$ anomaly expressed as $\ln \left[\mathrm{H}_{2} \mathrm{O}\right]$ ), with $\delta \mathrm{D}$, and with $\delta \mathrm{D}^{\prime}$ ( $\delta \mathrm{D}$ and $\delta \mathrm{D}^{\prime}$ anomaly expressed as $\left.\ln \frac{[\mathrm{HDO}]}{\left[\mathrm{H}_{2} \mathrm{O}\right]}\right)$. Black line: FTIR data; red line: nudged run IsoGSM data; green line: free run IsoGSM data. The hatched areas represent the $1 \sigma$ significance intervals. The open squares and error bars upon the bottom x-axis represent $R^{2}$ and $1 \sigma$ significance interval for column integrated data.

clearly reveal a connection between the AO index and the water transport pathways to Kiruna's lower troposphere.

The right panels of Fig. 13 depict the correlations with the AMO index. The most significant correlation is found for $\delta \mathrm{D}^{\prime}$ in the lower troposphere, where about $20 \%$ of the measured and nudged run $\delta \mathrm{D}^{\prime}$ anomalies can be explained by Atlantic SST anomalies. These correlations are significant on a 95\% significance level, and reveal a climate feedback: increased surface temperatures will increase SST, which will apparently lead to changes in Kiruna's lower tropospheric water vapour transport pathways. The free run model shows no correlations.

Figure 14 demonstrates that a consistent long-term dataset is mandatory for identifying the above described connections. It shows correlation plots between the Arctic Oscil- lation index and the $\delta \mathrm{D}$ anomalies as measured at Kiruna at an altitude of $1 \mathrm{~km}$ for different time scales (short-term, monthly, quarterly, and yearly). On short time scales there is a large scatter in the $\delta \mathrm{D}$ data due to the large day-to-day variability. On this time scale we cannot observe a clear connection between Kiruna's lower tropospheric $\delta \mathrm{D}$ and the $\mathrm{AO}$ index ( $R^{2}$ of only $6.3 \%$ ). This connection only becomes significant when averaging over longer time scales. When contemplating quarterly mean data the $R^{2}$ value is almost $40 \%$.

Figure 15 shows the correlation between the Izaña data and the Northern Atlantic Oscillation (NAO) index (left panels) and the Tropical Northern Atlantic (TNA) index (right panels). The time series of NAO and TNA indices are shown in Fig. 6. The NAO index describes northern hemispheric anomalies of the $500 \mathrm{mb}$ height. It represents large scale atmospheric anomalies. The TNA index is constructed from SST anomalies in the Tropical Atlantic between $5^{\circ} \mathrm{N}$ and $25^{\circ} \mathrm{N}$. We find a very strong and significant negative correlation between the the NAO index and the measured middle/upper tropospheric $\delta \mathrm{D}$ and $\delta \mathrm{D}^{\prime}$ quarterly mean anomalies (at a 99\% confidence level). The corresponding correlations with the model data are much weaker and not very significant. The measurements clearly suggest that the atmospheric anomalies described by the NAO index affect the water transport to Izaña's middle/upper troposphere. This manifests the large complexity of the water cycle in the subtropics. The model fails in capturing the complexity of the subtropics. This aspect is of great importance on a global scale, since the tropical dry zone is the key region of the water vapour feedback effect (Pierrehumbert, 1995; Spencer and Braswell, 1997; Held and Soden, 2000). Climate projection based on models that are not able to reproduce this important aspect of the Earth's climate system should be treated with great care.

In Fig. 10 we show that the $\delta \mathrm{D}$ variances in the measurement are significantly larger than in the model. The fact that about $70 \%$ of the measured middle/upper tropospheric $\delta \mathrm{D}$ variances (when averaged over a quarter) can be explained by the NAO means that a major part of the measured variance is real and not produced by random errors. It is a further proof of the good quality of the ground-based FTIR $\delta \mathrm{D}$ data.

The right panels of Fig. 15 show the correlations to the tropical northern Atlantic SST anomalies (as described by the TNA index). There is a very strong and significant correlation between the measured middle/upper tropospheric $\mathrm{H}_{2} \mathrm{O}$ amounts and the TNA index. About $60 \%$ of the measured $\mathrm{H}_{2} \mathrm{O}$ anomalies can be explained by anomalies in the SST of the tropical northern Atlantic. A significant positive correlation is also seen between the TNA index and the measured middle/upper tropospheric $\delta \mathrm{D}$. Tropical SST is well positively correlated with tropical upper tropospheric specific humidity (e.g. Minschwaner et al., 2006). Our observation of a strong correlation between tropical SST and the subtropical middle troposphere is a consequence of the direct connection between the tropical upper troposphere and the subtropical middle troposphere by means of the Hadley circulation. 

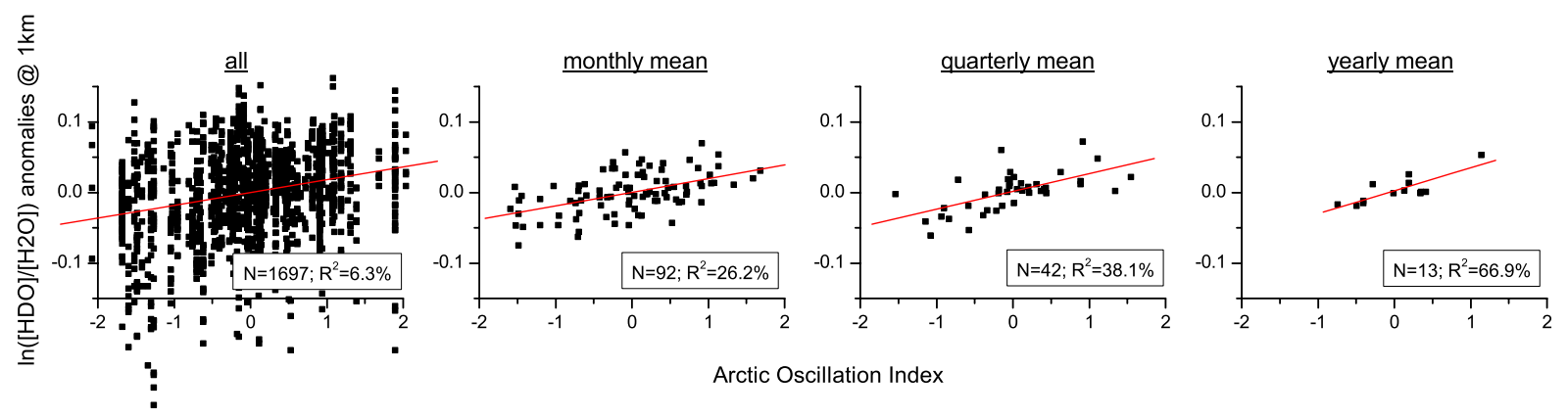

Fig. 14. Correlation plots between the $\mathrm{AO}$ index and $\delta \mathrm{D}$ anomalies (expressed as $\ln \frac{[\mathrm{HDO}]}{\left[\mathrm{H}_{2} \mathrm{O}\right]}$ ) at an altitude of $1 \mathrm{~km}$ at Kiruna. From the left to the right: all individual measurements, monthly mean data, quarterly mean data, yearly mean data. The respective number of data points $(N)$ and coefficients of determination $\left(R^{2}\right)$ are written in each panel.
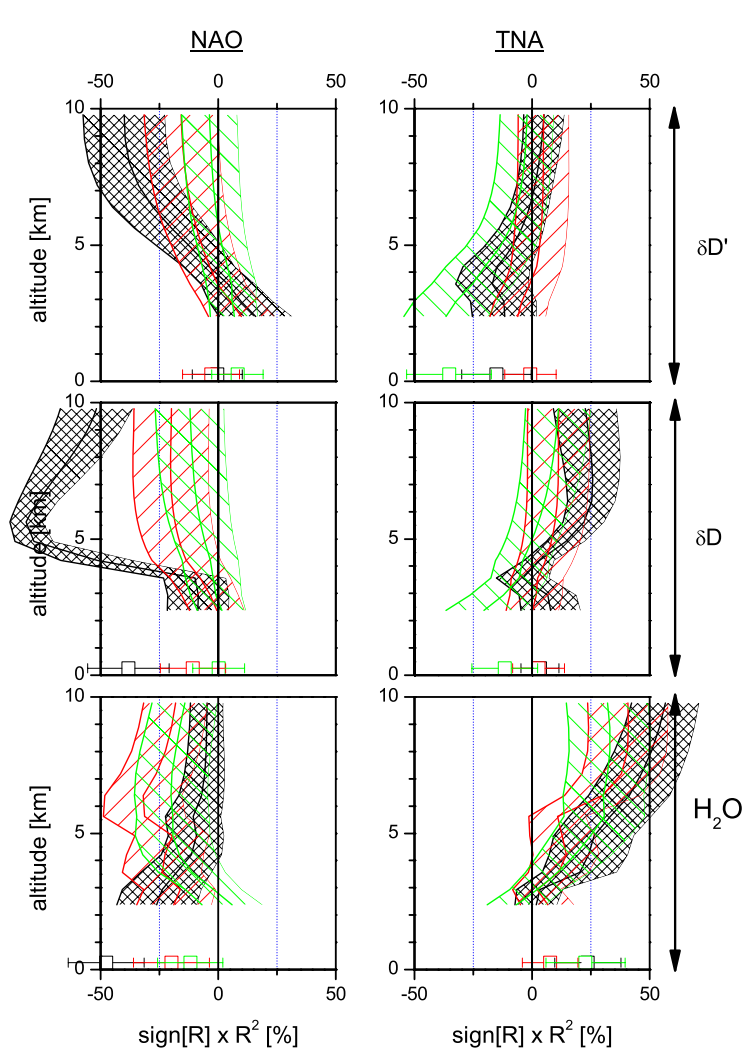

Fig. 15. Same as Fig. 13 but for Izaña and for correlations with the NAO and TNA indices.

The nudged model does not well capture the strength of the correlation between the TNA index and the subtropical middle tropospheric $\mathrm{H}_{2} \mathrm{O}$ anomaly (red curve in the bottom right panel), which might indicate that it underestimates the effectiveness of the connection between tropical upper troposphere and subtropical middle troposphere.

\section{Conclusions}

We examine the quality of ground-based FTIR $\delta \mathrm{D}$ remote sensing data by a comparison to an isotope incorporated AGCM and by correlations to atmospheric and oceanic anomalies. Firstly, we show that the day-to-day variability measured for up to 13 years at two very distinct sites is in reasonable agreement with the nudged AGCM data. Secondly, the measured $\delta \mathrm{D}$ anomalies correlate with atmospheric and oceanic anomalies. Both findings document the good quality of the FTIR $\delta$ D data and confirm the extensive theoretical error estimations of Schneider et al. (2006b).

Currently the ground-based FTIR technique is the only technique that can provide tropospheric profiles of $\mathrm{H}_{2} \mathrm{O}$ and $\delta \mathrm{D}$ over the long time periods and with the quality required for extensive studies of the atmospheric water cycle. At the subarctic site of Kiruna the measurements reveal a strong connection between lower tropospheric water transport pathways and the AO index. At the same time they suggest that these transport pathways will change in response to global warming (correlation between $\delta \mathrm{D}^{\prime}$ and AMO index). Furthermore, they reveal systematic spring to autumn differences concerning the processes that determine middle tropospheric water amounts. For the subtropical site of Izaña the FTIR data document the importance of the Hadley circulation and a strong correlation between middle/upper tropospheric water vapour transport pathways and the NAO index.

Tropospheric $\mathrm{H}_{2} \mathrm{O}$ and $\delta \mathrm{D}$ strongly vary with the actual synoptic situation. A comparison of model and measurement on short time scales is only meaningful when the model is nudged towards the meteorological fields of reanalysis data. Also on longer time scales the model significantly benefits from nudging. If not nudged towards reanalysis data and only driven by SST (AMIP-type model) the model is not able to reproduce the characteristic atmospheric patterns described by the NAO and $\mathrm{AO}$ indices and consequently their impact on $\mathrm{H}_{2} \mathrm{O}$ and $\delta \mathrm{D}$. Surprisingly, nudging is also important to capture the connection between the northern Atlantic 
SST and Kiruna's water cycle. These deficits of the AMIPtype model are unsatisfactory and in a future study it should be investigated if fully coupled ocean-atmosphere models perform better in this respect.

Even the nudged model fails in reproducing the spring $\delta \mathrm{D}$ maximum in the subarctic middle troposphere and the strong connection between the NAO index and the subtropical middle/upper tropospheric water balance. In particularly the latter is a severe deficit of a climate model since understanding the water balance in the tropical dry zones is essential for a correct modelling of the Earth's radiative cooling.

The water cycle and its interplay with climate change, like the response of the water cycle on SST changes, are of ultimate importance for understanding and predicting climate. Current AGCMs are often not able to correctly reproduce the water cycle, thereby challenging the reliability of climate prediction models: without progress in modelling the water cycle, climate predictions will remain doubtful. The FTIR water vapour isotopologue measurements of Kiruna and Izaña, in representation of the entire NDACC FTIR network, reveal connections of the water cycle to atmospheric large scale dynamics and SST. We demonstrate that the capability of the ground-based FTIR technique in monitoring the vertical distribution of tropospheric $\mathrm{H}_{2} \mathrm{O}$ and $\delta \mathrm{D}$ together with the long-term characteristic of the data is the key for investigating these water cycle complexities. In this context reanalysing the historic NDACC FTIR spectra with respect to tropospheric water isotopologue ratio profiles and comparing the dataset to isotope incorporated AGCMs promises unprecedented opportunities for improving climate prediction models.

Acknowledgements. M. Schneider is funded by the Deutsche Forschungsgemeinschaft (project RISOTO: Geschäftszeichen SCHN 1126/1-1 and 1-2). We are grateful to the Goddard Space Flight Center for providing the temperature and pressure profiles of the National Centers for Environmental Prediction via the automailer system and to U. Raffalski for assisting us with the FTIR experiment in Kiruna.

Edited by: Thomas Röckmann

\section{References}

Blumenstock, T., Kopp, G., Hase, F., Hochschild, G., Mikuteit, S., Raffalski, U., and Ruhnke, R.: Observation of unusual chlorine activation by ground-based infrared and microwave spectroscopy in the late Arctic winter 2000/01, Atmos. Chem. Phys., 6, 897905, 2006,

http://www.atmos-chem-phys.net/6/897/2006/.

Chen, T.-C.: Characteristics of African Easterly Waves depicted by ECMWF Reanalysis for 1991-2000, Mon. Weather Rev., 134, 3539-3566, 2006.

Cook, K. H.: Generation of the African Easterly Jet and its role in determinating West African precipitation, J. Climate, 12, 1165$1184,1999$.
Craig, H.: Standard for Reporting Concentrations of Deuterium and Oxygen-18 in Natural Waters, Science, 133, 1833-1834, 1961.

Dessler, A. E. and Sherwood, S. C.: A model of HDO in the tropical tropopause layer, Atmos. Chem. Phys., 3, 2173-2181, 2003, http://www.atmos-chem-phys.net/3/2173/2003/.

Ehhalt, D. H.: Vertical profiles of HTO, HDO, and $\mathrm{H}_{2} \mathrm{O}$ in the Troposphere, Rep. NCAR-TN/STR-100, Natl. Cent. for Atmos. Res., Boulder, Colorado, USA, 1974.

Frankenberg, C., Yoshimura, K., Warneke, T., Aben, I., Butz, A., Deutscher, N., Griffith, D., Hase, F., Notholt, J., Schneider, M., Schrejver, H., and Röckmann, T.: Dynamic processes governing lower-tropospheric $\mathrm{HDO} / \mathrm{H}_{2} \mathrm{O}$ ratios as observed from space and ground, Science, 325, 1374-1377, 2009.

Gates, W. L.: AMIP: The Atmospheric Model Intercomparison Project, Bull. Am. Meteorol. Soc., 73, 1962-1970, 1992.

Gardiner, T., Forbes, A., de Mazière, M., Vigouroux, C., Mahieu, E., Demoulin, P., Velazco, V., Notholt, J., Blumenstock, T., Hase, F., Kramer, I., Sussmann, R., Stremme, W., Mellqvist, J., Strandberg, A., Ellingsen, K., and Gauss, M.: Trend analysis of greenhouse gases over Europe measured by a network of ground-based remote FTIR instruments, Atmos. Chem. Phys., 8, 6719-6727, 2008, http://www.atmos-chem-phys.net/8/6719/2008/.

Hase, F., Hannigan, J. W., Coffey, M. T., Goldman, A., Höpfner, M., Jones, N. B., Rinsland, C. P., and Wood, S. W.: Intercomparison of retrieval codes used for the analysis of high-resolution, ground-based FTIR measurements, J. Quant. Spectrosc. Ra., 87, 25-52, 2004.

Held, I. M. and Soden, B. J.: Water Vapour Feedback and Global Warming, Annu. Rev. Energy Environ., 25, 441-475, 2000.

John, V. O. and Soden, B. J.: Temperature and humidity biases in global climate models and their impact on climate feedbacks, Geophys. Res. Lett., 34, L18704, doi:10.1029/2007GL030429, 2007.

Kanamitsu, M., Kumar, A., Juang, H.-M. H., Schemm, J.-K., Wang, W., Yang, F., Hong, S.-Y., Peng, P., Chen, W., Moorthi, S., and Ji, M.: NCEP dynamical seasonal forcast system 2000, Bull. Am. Meteorol. Soc., 83, 1019-1037, 2002.

Kurylo, M. J. and Zander, R.: The NDSC - Its status after 10 years of operation, Proceedings of XIX Quadrennial Ozone Symposium, Hokkaido University, Sapporo, Japan, 167-168, 2000.

Minschwaner, K., Desler, A. E., and Sawaengphokhai, P.: Multimodel Analysis of the Water Vapor Feedback in the Tropical Upper Troposphere, J. Climate, 19, 5455-5465, 2006.

Pierrehumbert, R. T.: Thermostats, Radiator Fins, and the Local Runaway Greenhouse, J. Atmos. Sci., 52, 1784-1806, 1995.

Rodgers, C. D.: Inverse Methods for Atmospheric Sounding: Theory and Praxis, World Scientific Publishing Co., Singapore, ISBN: 981-02-2740-X, 2000.

Schneider, M., Hase, F., and Blumenstock, T.: Water vapour profiles by ground-based FTIR spectroscopy: study for an optimised retrieval and its validation, Atmos. Chem. Phys., 6, 811-830, 2006a, http://www.atmos-chem-phys.net/6/811/2006/.

Schneider, M., Hase, F., and Blumenstock, T.: Ground-based remote sensing of $\mathrm{HDO} / \mathrm{H}_{2} \mathrm{O}$ ratio profiles: introduction and validation of an innovative retrieval approach, Atmos. Chem. Phys., 6, 4705-4722, 2006b, http://www.atmos-chem-phys.net/6/4705/2006/.

Schneider, M., Redondas, A., Hase, F., Guirado, C., Blumenstock, T., and Cuevas, E.: Comparison of ground-based Brewer and 
FTIR total column $\mathrm{O}_{3}$ monitoring techniques, Atmos. Chem. Phys., 8, 5535-5550, 2008, http://www.atmos-chem-phys.net/8/5535/2008/.

Schneider, M. and Hase, F.: Ground-based FTIR water vapour profile analyses, Atmos. Meas. Tech., 2, 609-619, 2009, http://www.atmos-meas-tech.net/2/609/2009/.

Schneider, M., Romero, P. M., Hase, F., Blumenstock, T., Cuevas, E., and Ramos, R.: Continuous quality assessment of atmospheric water vapour measurement techniques: FTIR, Cimel, MFRSR, GPS, and Vaisala RS92, Atmos. Meas. Tech., 3, 323338, 2010.

Spencer, R. W. and Braswell, W. D.: How Dry is the Tropical Free Troposphere? Implications for Global Warming Theory, Bull. Amer. Meteor. Soc., 78, 1097-1106, 1997.

Sturm, C., Zhang, Q., and Noone, D.: An introduction to stable water isotopes in climate models: benefits of forward proxy modelling for paleoclimatology, Clim. Past, 6, 115-129, 2010, http://www.clim-past.net/6/115/2010/.

Taylor, C. B.: The vertical variations of the isotopic concentrations of tropospheric water vapour over continental Europe and their relationship to tropospheric structure, N. Z. Dep. Sci. Ind. Res., Inst. Nucl. Sci. Rep., INS-R-107, 44 pp., 1972.

van Hook, W. A.: Vapor pressures of the isotopic waters and ices, J. Phys. Chem., 72, 1234-1244, 1968.

Webster, C. R. and Heymsfield A. J.: Water isotope ratios D/H, ${ }^{18} \mathrm{O} /{ }^{16} \mathrm{O},{ }^{17} \mathrm{O} /{ }^{16} \mathrm{O}$ in and out of clouds map dehydration pathways, Science, 302, 1742-1745, 2003.
Worden, J. R., Bowman, K., Noone, D., Beer, R., Clough, S., Eldering, A., Fisher, B., Goldman, A., Gunson, M., Herman, R., Kulawik, S. S., Lampel, M., Luo, M., Osterman, G., Rinsland, C., Rodgers, C., Sander, S., Shephard, M., and Worden, H.: TES observations of the tropospheric $\mathrm{HDO} / \mathrm{H}_{2} \mathrm{O}$ ratio: retrieval approach and characterization, J. Geophys. Res., 111(D16), D16309, doi:10.1029/2005JD006606, 2006.

Worden, J. R., Noone, D., Bowman, K., Beer, R., Eldering, A., Fisher, B., Gunson, M., Goldman, A., Herman, R., Kulawik, S. S., Lampel, M., Osterman, G., Rinsland, C., Rodgers, C., Sander, S., Shephard, M., Webster, C. R., and Worden, H.: Importance of rain evaporation and continental convection in the tropical water cycle, Nature, 445, 528-532, 2007.

Yoshimura, K., Kanamitsu, M., Noone, D., and Oki, T.: Historical isotope simulation using Reanalysis atmospheric data, J. Geophys. Res., 113, D19108, doi:10.1029/2008JD010074, 2008.

Yoshimura, K. and Kanamitsu, M.: Dynamical global downscalling of global reanalysis, Mon. Weather Rev., 136(8), 2983-2998, 2008.

Zahn, A.: Constraints on 2-Way Transport across the Arctic Tropopause Based on $\mathrm{O}_{3}$, Stratospheric Tracer $\left(\mathrm{SF}_{6}\right)$ Ages, and Water Vapor Isotope (D, T) Tracers, J. Atmos. Chem. 39, 303325, 2001. 